\title{
Media influence on dietary practices of college going girls
}

\author{
ANSHU JOHRY AND SANGITA SRIVASTAVA
}

Received: 07.07.2014; Accepted: 20.11 .2014

See end of the paper for authors' affiliations

\section{ANSHU JOHRY}

Department of Home Science,

University of Allahabad,

ALLAHABAD (U.P.) INDIA

Email: anshujohry@ymail.com
ABSTRACT : This study aimed to research into the effects of media exposure to slimming and fitness advertisements on body dissatisfaction, eating disorder symptomatology and weight loss behaviour and the relations between body dissatisfaction and extreme weight loss behaviour. A random sample of 250 students all of them belonging to Allahabad university completed a set of questionnaire body shape questionnaire, eat-26 and weight loss behaviour scale result indicates that fashion or beauty magazines, social comparisons, overall appearance dissatisfaction and critical body image processing are important predictors of body image and eating disturbances for adolescent girls the result highlights the need for media activism to help change the current normative body discontent of women in India.

KEY WORDS: Mass media, Eating disorder, Body dissatisfaction, Weight loss behaviour

- HOW TO CITE THIS PAPER : Johry, Anshu and Srivastava, Sangita (2014). Media influence on dietary practices of college going girls. Asian J. Home Sci., 9 (2) : 628-632. 